\title{
The Dynamics of Social Indicator Research for California's Central Valley in Transition
}

\author{
Robin M. DeLugan • Marcia D. Hernandez • Dari E. Sylvester • \\ Simón E. Weffer
}

Accepted: 1 April 2010/Published online: 20 April 2010

(C) The Author(s) 2010. This article is published with open access at Springerlink.com

\begin{abstract}
How can social indicator research improve understanding of community health as well as inform stakeholders about the assets disadvantaged communities have for coping with disparities? This paper describes the development and evolution of the Partnership for Assessment of Communities (PAC) and its best practices for social indicator research. The PAC will be of interest to researchers across multiple disciplines for a number of reasons. First, PAC is a working model of best practices for multidisciplinary scholarly inquiry. Second, it has developed an integrated model of quantitative and qualitative methodology to define and measure community health as compared to traditional quality-of-life indicators. Third, it serves as an example of "action research," in that the findings have the potential to make an impact on community stakeholders and policy outcomes in the greater Central San Joaquin Valley of California, a region characterized by deep social and economic disparities.
\end{abstract}

Keywords Disparities - Indicator selection - Community health · Quality of life · San Joaquin Valley, California

How can social indicator research impact inequalities that undermine local communities, as well as inform stakeholders about the assets that disadvantaged communities have for coping with social and economic disparities? Can social indicator research provide data that extends beyond individual or household quality-of-life to offer broader measures of the health of a community? Further, how can the analysis of social indicators, when applied to select urban and rural communities, provide data on locally significant conditions, as well as broader regional dynamics? The Partnership for Assessment of Communities (PAC) is a

R. M. DeLugan $(\bowtie) \cdot$ S. E. Weffer

University of California, Merced, CA, USA

e-mail: rdelugan@ucmerced.edu

M. D. Hernandez - D. E. Sylvester

University of Pacific, Stockton, CA, USA 
multidisciplinary social science project with collaborators from three institutions of higher education tasked with developing a 10-year study of California's Central San Joaquin Valley, an under-resourced region that is undergoing rapid social and economic transformation. Regional transformations include urbanization and concomitant reduction of agricultural lands for housing development, and population growth with new arrivals from other regions of the state. The international influx includes migrants participating in seasonal agricultural labor and immigrants. Rapid change has affected various measures of qualityof-life. According to a recent article about environmental transformations in the region, "Farmers blame the area's blight on a 'man-made drought' brought on by increasingly strict environmental regulations, but that is only the beginning of the story. There's also the crushing confluence of political negligence, drought, and a century's worth of unbridled growth" (Paul 2009). In fact, the complex irrigation systems built throughout the greater region that comprises the San Joaquin Valley were originally built for sixteen million people and a moderate amount of agriculture, but today serves 38 million featuring millions of acres of farmland (ibid.). Poverty, high unemployment, low educational attainment, low voter turnout, limited access to healthcare insurance and primary care physicians, along with the state's highest rates of asthma, diabetes and other chronic health risks are to be counted among the pressures that impact local communities in the region.

This article examines the PAC's utilization of social indicators in pilot research. With a primary focus on research design and methodology versus emphasis on preliminary data findings, the article provides an example of how a multidisciplinary team accommodates both academic research interests and the interests of various community stakeholders in multiple communities to better understand conditions in California's Central San Joaquin Valley. Offered are the project's conceptualization of health of community and its relationship to "typical" quality-of-life based research, including how it is applied to select urban neighborhoods and rural unincorporated areas in the Central San Joaquin Valley. Further provided is an examination of how a research focus on the health of community aims to enhance community-engagement in the process. The project design envisions multiple dimensions to community-engagement including: roles as academic researchers and university representatives, the opportunity for student researchers to connect with local communities, and reinforcing residents' own civic engagement with community issues.

\section{Background: Partnership for Assessment of Communities}

The PAC collaboration was initially created in 2006. In June 2005, California Governor Arnold Schwarzenegger, in recognition of the importance of the San Joaquin Valley to the state as a whole, issued Executive Order No. S-5-05, 2005 (renewed in 2008 for an additional 3 years through Executive Order No. S-17-08) creating the California Partnership for the San Joaquin Valley. The Partnership was charged with improving the economic wellbeing of the San Joaquin Valley and the quality of life of its residents (California Partnership for the San Joaquin Valley 2006). The Partnership tasked the PAC collaborators with developing a study to track changes in local populations over time on a variety of measures identified in the San Joaquin Valley Strategic Action Proposal. The measures include access to healthcare insurance and to primary care physicians, asthma rates, ozone exceedence, and levels of educational attainment, income, employment and poverty. The study was designed to track changes in individual communities that could result from concerted efforts to improve disparities in the region. 
By monitoring a series of indicators in selected urban and rural communities in the Central San Joaquin Valley, PAC is tracking the changes that result from the implementation of the aforementioned strategic action recommendations, and will continue to do so over a span of 10 years. PAC collaborators are scholars with professional backgrounds in several disciplines (including Anthropology, Political Science and Sociology) and belong to different research and educational institutions in the Central San Joaquin Valley (including University of California-Merced, California State University-Fresno, and University of the Pacific-Stockton). The PAC multi-disciplinary and multi-institutional team was convened by the Great Valley Center, a nonprofit organization focused on "supporting the economic, social, and environmental well-being of California's Great Central Valley". ${ }^{1}$ The Great Valley Center is also a formal partner of the University of California-Merced.

PAC was charged with developing a longitudinal 10-year project that will document conditions in the region, and note changes in a number of indicators illustrative of the region's disparities. The PAC team selected six specific locations, comprised of urban and rural unincorporated areas from the northern, central and southern areas of the region, as a focus for the long-term study. Census-tracts defined the boundaries of the selected geographic locations as well as the level at which reported data will be sought when possible. For the pilot period (2007-2009) adult residents within selected census-tracts were surveyed and interviewed about conditions in their lives at the individual, household and community level. In addition, a survey was prepared for organizations that serve the targeted areas. The motive for the organization survey was that examining faith-based, non-governmental, and service-providing organizations would provide useful information on what these organizations perceived as community priorities, the particular interventions or services provided by the organizations, and the extent to which organizations were networked or working together to address common issues or priorities.

\subsection{San Joaquin Valley: A Region in Transition}

As a subset of the greater San Joaquin Valley, the Central San Joaquin Valley (Central Valley) encompasses the eight counties of Merced, San Joaquin, Stanislaus, Fresno, Kern, Kings, Madera and Tulare. It includes a 27,280-mile area, and a population of 3.3 million (or approximately $10 \%$ of California's population). ${ }^{2}$ The region is notable within the state of California and in the US for its profitable agricultural industry, endemic poverty and deep social disparities, cultural diversity borne of international migration, its environmental pressures such as poor air quality and contests over access to water, and for its recent and rapid urbanization including being zone zero in the current housing foreclosure crisis. For example, Stockton benefited from the housing boom, and now is experiencing the economic downturn from the bust. Stockton also recently received the dubious distinction of topping the Forbes.com misery index with the city ranking "in the bottom seven in four of the nine categories...commute times, income tax rates, unemployment and violent crime" (Badenhausen 2009). Merced and Fresno have also experienced their

\footnotetext{
${ }^{1}$ Great Valley Center website. Accessed 5/27/09. www.greatvalley.org.

2 “California's San Joaquin Valley: A Region in Transition," Washington, DC: Congressional Research Services/Library of Congress, 2005). This same report compares the poverty in San Joaquin Valley to Appalachia.
} 
share of social and economic problems due to a decrease in economic activities in the Central Valley. Merced's unemployment rose steadily from mid-2008 to mid-2009, to reach " 17.6 percent as of June 2009 [much higher than] national unemployment which stood at 9.7 in June" (Reily 2009); during the same reporting period Fresno's unemployment rate was $15.2 \%$ (Sheehan 2009). In July of 2009, HUD Secretary Shaun Donovan surveyed empty lots in the Central Valley to assess the fallout and was reported to observe, "I've been to New Orleans [after Hurricane Katrina] and to Cedar Rapids [Iowa] a year after the floods, and some of this reminds me of the same streets I walked down" (Paul 2009).

While there are a handful of recent regional studies on specific topics (Baldassare 2006; Bengiamin et al. 2005; California Partnership for the San Joaquin Valley 2006; Congressional Research Service 2005), the Central San Joaquin Valley lacks consistent, longitudinal data about local communities and their wellbeing. The 10-year longitudinal PAC project attempts to fill that gap in research. The PAC demonstrates a process of collaborative multidisciplinary research that addresses the interests of multiple stakeholders in a model that emphasizes community engagement. Through the use of data derived from objective and subjective social indicators, findings examine the quality-of-life of individual residents, and perceptions and experiences of residents that provide insight into local community dynamics and into problem-solving solutions. The project's focus on community problem solving holds promise to not only gather important data useful for tracking changes in local conditions, but also has the potential of offering a unique contribution to local efforts to improve community health. It has also required engaging with multiple stakeholders and enabling them to influence the research design.

\section{Social Indicator Research to Understand Community Dynamics}

The PAC project adds to the rich discussion about the changing role and function of social indicator research. The project's research design and social indicator selection responds to diverse stakeholders seeking data about individual experience and about community conditions. The guiding conceptual framework engages sociological theory to explain why an emphasis on quality-of-life alone is insufficient for understanding the factors that influence community life and wellbeing. It also aspires to connect social indicator research to community engagement and action, discussed subsequently in this paper.

Swain and Hollar (2003) group social indicator projects into four primary types: qualityof-life, sustainability, healthy-community, and government benchmarking and performance measurement. In particular, the PAC research bridges the distinction that Swain, Hollar, and others make between quality-of-life and community health indicators (Dluhy and Swartz 2006). While initially tasked to track reported data (i.e., income, employment, educational attainment) on local communities in the region, PAC researchers were determined to expand the research to include qualitative data provided by local residents about their individual and household experiences and their ideas about community dynamics. It is the combination of traditional quality-of-life indicators with indicators that aim to better understand community dynamics that marks the uniqueness of the PAC project.

To what extent can indicators inform us about community dynamics and wellbeing? The American Academy of Arts and Sciences coined the term "social indicators" as an attempt "to develop a system that would allow them to anticipate change and assess the impact and 
value of their programs" (Marinrogers et al. 2009, p. 28). The Academy defined social indicators as "statistics, statistical series and all other forms of evidence that enable us to assess where we stand and are going with respect to our values and goals" (ibid.). Social indicator projects range in size, scope and goals. Many social indicator projects have general objectives such as assisting in the monitoring of goals for government agencies, while others may be more specialized such as monitoring the health of children or environmental measures.

Nevertheless, social scientists are not unanimous in their views about social indicators and their function in research. For instance, Cobb and Rixford's (1998) review of the history of the social indicator movement points out the conflicts that researchers have about the function of social indicators. Should social indicators primarily monitor and describe conditions, or should they be used purposefully to guide next steps? Other debates pertain to how social indicators are developed and the degree to which their use for data collection should emphasize objectivity and theoretical generalization. Some theorists question whether social indicators ought to primarily be based on theoretical models with testable hypotheses, or should first and foremost be a measurement of social conditions. In reverse, should social indicators be developed first to compile data about social conditions to enhance a problem-solving role before theoretical generalization? The objectivity connected to social indicator research either in the data preserved or in the partisanship of the data collector has been examined in the academic literature alongside general debates about the objectivity of science.

Kitchen and Muhajarine (2008) demonstrate how these debates about the role and function of social indicators were illustrated in quality-of-life research beginning in the 1970s. Originally quality-of-life research focused primarily on objective data culled from governmental or related reports on topics such as levels of gross domestic product (GDP), poverty, income, education, and employment. Subjective measures such as perception or satisfaction with one's community were also introduced. Perceptual measures enriched the objective data by reflecting the lived experiences and meanings that objective measures could not effectively describe.

Between the late 1970s and early 1990s, quality-of-life indicator research not only incorporated new perspectives but also attracted new stakeholders such as local business, government, and the communities themselves. In addition, the scale of quality-of-life studies also transformed, ranging from the study of entire cities to the study of particular neighborhoods. One important feature of quality-of-life research became the "imperative to see change and to improve the circumstances of people" (Kitchen and Muhajarine 2008:2). This feature illustrated how an emphasis on problem solving interacted with increased attention to community involvement both in quality-of-life indicator selection and as partners in research.

Cobb and Rixford (1998) view the purpose of social indicator research more broadly as "to alert the public and policymakers about the existence and cause of problems so that they might be solved" (p. 29). As such, they are proponents of indicator research that goes beyond descriptive indicator reports to research that advances the understanding of why certain social conditions exist, and where indicator data attempts to affect outcomes. Cobb and Rixford take the lessons learned from the history, debates, and conflicts surrounding the selection and function of social indicators, and the role of social indicator research, and offer the guidelines on the following page for a more analytical approach to indicator research.

The conceptual framework and research design of the PAC project heeds much of the advice of Cobb and Rixford. Of particular interest is the extent to which well-placed social indicators can become guides for problem-solving action. The ability of social indicators to 
Historical Lessons from Social Indicators Movements (Cobb and Rixford 1998: 14-30)

Having a number doesn't necessarily mean that you have a good indicator:

Social indicators that reveal a number (a quantity) but not a quality (may be inferred) of what is being measured are less likely to be of value

Effective indicators require a clear conceptual basis:

Clarify what you intend to measure when using a particular indicator

There's no such thing as a value-free indicator:

Indicators and their reporting are not neutral, acknowledging the values or concept that underlie particular indicators may lead to a more fair or balanced presentation

Comprehensiveness may be the enemy of effectiveness:

A few insightful indicators may be more effective than having too many indicators

The symbolic value of an indicator may outweigh its value as a literal measure:

Indicator measures, particularly when conglomerated into an index number, can function as metaphors; for examples, the population of the spotted owl as a symbol of ecological values, or Gross Domestic Product (GDP) as a symbol of wellbeing

Do not conflate indicators with reality:

Indicators are only a partial measurement of complex reality. Avoid confusing the indicator data with reality by developing multiple indicators for the same phenomenon

A democratic indicators program requires more than good public participation processes:

The broad representation, participation, and consensus of stakeholders to determine social indicators may produce indicators that do little to challenge prevailing practices

Measurement does not necessarily induce appropriate action:

Indicators are a tool for change when part of a larger plan and where there is political momentum for action

Better information may lead to better decisions and improved outcomes, but not as easily as it might seem:

Indicators can provide information that can help to make changes, but they are not the only form of information for affecting perceptions, behaviors, or policy

Challenging prevailing wisdom about what causes problem is often the first step to fixing it:

Addressing a problem through indicator research can involve altering its definition, or the common understanding of it, including why a problem exists

To take action, look for indicators that reveal causes, not symptoms:

Indicator research needs a theory or idea about what causes problems and what enables them to be solved

You are more likely to move from indicators to outcomes if you have control over resources:

Determining who has the power to take action can help clarify what outcomes you expect from your indicators report

monitor change and/or affect change by improving understanding of social problems faced by communities, such as safety and security in neighborhoods, as well as changes in communities such as social mobility, point toward a more active role for social indicator research that extends beyond purely academic interests. In this regard, the indicators selected and data collected by PAC researchers are particularly connected to social science theory about social efficacy, social cohesion, and civic engagement, dynamics that arguably are connected to community health and wellbeing. As such the PAC research design draws on other studies that measure dynamics such as social cohesion and social efficacy (Sampson et al. 1997) as well as studies that measure civic and political participation (Brady et al. 1995).

The PAC project engages traditional measures of quality-of-life with additional social indicators to, on one hand, examine and monitor problems that have already been targeted by key stakeholders for transformation; and, on the other hand, to illuminate factors (including community assets) that are already at work towards strengthening community despite low quality-of-life indicators. The project is also capitalizing on political attention focused on addressing endemic disparities in the San Joaquin Valley, a region of California 
undergoing rapid transformation. Further, by building community engagement and response into the project, PAC aspires to be an example of action research.

\section{Issues of Methodology: Who Selects the Indicators?}

The process of selecting indicators to measure social dynamics can involve multiple stakeholders. It can involve indicators chosen by top-down interests of governments and other stakeholders, to more participatory processes of "bottom-up" community involvement. The PAC research began with a mandate through the Governor's initiative to design a project that would monitor specific regional disparities; thus governmental and quasigovernmental stakeholders provided the study with its initial social indicators (listed below). These indicators, best described as objective quality-of-life indicators, correspond with the action areas of work teams of the California Partnership for the San Joaquin Valley, and are summarized as follows:

- Economic conditions (unemployment, per capita and median household income, population below poverty line)

- Education (high school and college graduation rates, high school and college enrollment and drop out rates)

- Environmental and natural resource issues (specifically ozone exceedence rates and water consumption)

- Healthcare access and availability

- Asthma rates

- Technological divide

- Transportation

The above social indicators incorporated into the PAC research design were strategic in that they meshed with regional social development goals identified as priorities through working groups funded by the Governor's Office and the California Partnership for the San Joaquin Valley. PAC researchers began to collect quantitative information on these indicators from local, state and federal agencies and organizations, endeavoring to locate data at the census tract level when possible.

However, the research team quickly came to the conclusion that gross statistics, even local statistics, can overlook critical dimensions relating to quality-of-life. This realization led to the development of a qualitative research component. Surveys were adjusted to also gather data on local community involvement, civic participation, healthcare issues including insurance, access to primary care physicians, household occurrences of asthma or diabetes, transportation and mobility issues, safety and security of neighborhoods. The qualitative data collection involves detailed face-to-face surveys with residents and informational interviews with key community stakeholders such as public officials, representatives of faith-based organizations, non-profit organizations, and service providers. Other qualitative methodologies include phone interviews and ethnography to gain a more complete picture of the selected communities. These methods have been particularly useful for producing information regarding targeted areas for which readily available data does not exist Perhaps one of the most important aspects of the qualitative research is that the interview respondents have an opportunity to reflect and offer subjective comments about their experiences and their opinion of how community wellbeing can be improved. Such information of an individual, personal nature is unobtainable from restrictive quantitative methods with limited opportunities for response. 


\section{Social Indicator Selection to Theorize "Health of Community"}

An academic's interest in and commitment to theory, model making, hypothesis testing, and analysis does not necessarily disappear as community involvement increases. Rather than limit the PAC research to a solely descriptive tracking over time of objective qualityof-life social indicators, the team sought to expand the scope to study individual perceptions, practices, and dynamics that may connect (or not) to an individual's sense of belonging and engagement with the local community. PAC efforts to deepen the project theoretically and conceptually were accompanied by a commitment to community engagement and to finding ways to maximize community contribution to the research process.

The question of whether research outcomes vary when community members determine the indicators to be measured has been examined in diverse case studies and contexts (Muhajarine et al. 2008). While a participatory model of engagement can yield "buy in" (cooperation, rapport, and a sense of ownership or commitment by community residents), the need for quantifiable and objectively verifiable indicators can require input beyond that of individual community members. Therefore, a tension may exist between academic standards for indicator selection and measurement, and a community's interests likely guided less by academic standards.

To enable the comparisons of research data across regions, suitable indicators may need to be selected that extend beyond the immediate interests of particular community members. The interest of the PAC team to develop a longitudinal project that allows comparison with nation-wide studies motivated an additional selection of certain subjective social indicators and other measures that rely on qualitative data. These indicators focused primarily on the perception of local community, in particular aspects such as sense of safety, willingness to work with neighbors, and shared values. In addition individuals were asked concrete questions about their modes of civic participation (from volunteering to voting). Perceptions of neighbors and community would allow us to analyze dynamics such as social cohesion and social efficacy as factors in community health and wellbeing. These questions come from the work of Sampson and his co-authors in a 1997 article in Science that examines the notion of neighborhood efficacy. The article uses data from the Project on Human Development in Chicago Neighborhoods (PHDCN), to create two sets of measures: social control and social cohesion. When these two measures are combined it creates a measure of social efficacy. The study suggests that even the most disadvantaged communities may have high social cohesion. This applies directly to the goals of the PAC project to move beyond merely individual and household quality-of-life indicators as a way to measure the health of a community.

Communities with low quality-of-life indicators could still have high levels of social control and/or cohesion. This results in a more engaged community, as members feel efficacious, able to make or prevent changes in the areas in which they live. It can also illuminate how individuals in rural and urban communities contend with social problems such as poverty and high unemployment (Docherty et al. 2001; Sherman 2008). Researchers have found that survival strategies for poverty in urban settings permit residents to engage in a wide range of activities, including unethical or morally questionable behavior according to mainstream American standards (such as selling drugs) and still feel part of the community (Anderson 1990; Duneier 1999). Although many strategies may not seem socially desirable or morally sound, nonetheless, individuals are often able to choose between economic maximization and cultural optimization (Wilson 1996). [Yet] the same does not necessarily hold true in rural areas, in which mainstream American culture is 
often more pervasive and hegemonic (Larson 1978; Snyder and McLaughlin 2004), and alternative lifestyles such as illegal activities are less plentiful (Sherman 2008: 892).

Sherman's (2008) research indicates that moral capital, defined as behavior dictated by mainstream American values and morals, takes on a heightened meaning in rural communities as it is a tradable commodity for economic capital (job opportunities) and social capital (community support). Social indicator research that examines the dynamics of social cohesion and efficacy in specific community settings can illuminate the everyday strategies and practices of coping and survival. This can be valuable information to policymakers and scholars.

During the planning phase PAC researchers discussed what the individual survey would measure, why, and how. As indicated above, the California Partnership for the San Joaquin Valley asserted the need for standard quality-of-life data. In addition, the research team sought to develop a project that could find national or international comparison. Understanding this project as an opportunity to monitor local communities that experience high degrees of disadvantage and inequality, while also recognizing how under-resourced communities positively function, the research endeavored to construct a "health of community" index that allows comparison across our urban and rural communities and compliments (or counterpoints) the quality-of-life data collected. ${ }^{3}$ Of central importance was an understanding of "neighborhoods" as units where change occurs, as well as units through which change may be brought about. Data collected from individual community members enables the testing of hypotheses around how and if (for example) social cohesion, volunteerism, civic involvement and other community participation correlates positively (or negatively) with quality-of-life, providing indications of a more or less "healthy" community.

Unlike current community efficacy and quality-of-life research, the PAC research team is applying social indicators tied to social cohesion and efficacy to a unique regional setting and examines urban and rural communities of varying size and isolation. As referenced above, PAC surveys include the following social indicators based on subjective qualitative information:

- Crime and Safety (security of neighborhood, real and perceived sense of safety)

- Educational Mobility (compared to parents' education completed)

- Health Insurance Coverage and Access to Primary Care Physician

- Household incidence of Asthma, Inhaler Use, and Diabetes

- Housing (effects of foreclosure crisis on family/neighborhood)

- Transportation expenses (effects of spike in gasoline prices)

- Stability of residence, mobility within region, and (im)migration

- Well-being, community participation and civic involvement

To gain data on the perception-based indicators, Likert scaled questions were constructed to correspond with existing social science research that allows a comparison of the PAC findings of California's Central San Joaquin Valley with other US urban and rural locations (Sampson et al. 1997; Brady et al. 1995). As mentioned above, the study will also research the role and impact that community-based organizations (including faith-based organizations) have on quality-of-life related issues. In addition, the effect of networking and collaboration among community-based organizations is considered (Ammerman 2005;

\footnotetext{
3 The construction of an index for health of community can be compared to Epley and Mohan (2008) who examine community quality-of-life through analysis of cross-sectional indicators.
} 
Bailey and McNally Koney 1996; Galaskiewicz and Bielefeld 1998). The goal of the pilot research is to generate baseline data from which changes over time can be measured.

PAC preliminary findings illustrate rural and urban differences in social efficacy measures (see Table 1). Despite lower quality-of-life measures, the rural communities have higher measures of social control and social cohesion that combine for a measure of social efficacy. By combining measures of social efficacy with measures of civic engagement, identified in the research as a number of practices that range from voting to volunteerism, the PAC endeavors to construct a measure of health of community.

In addition to the health of community measure, the PAC research is recording the perceptions that residents have about obstacles to community health and wellbeing as well as community assets (see Table 2). Preliminary findings indicate much agreement about obstacles and assets. PAC collaborators argue that in addition to the measures of health of community discussed above, data on perceived obstacles and assets to community health are useful to share with residents to create a community engagement feedback loop with the ongoing research. Arguably, illustrating points of consensus will assist residents to work together to devise strategies for promoting community health.

\section{Locally Significant Research That Makes a Difference in Communities}

While charged to develop a regional study, the focus on a selection of small-scale urban neighborhoods and unincorporated rural communities provided an opportunity to place the PAC research in the context of locally significant issues. The various stakeholders in the PAC regional study extend from the Governor's Office, to local residents in selected communities, to the interests of multidisciplinary team of academics and to the graduate and undergraduate students who not only assist in the research but who are also often local residents. Many stakeholders at the local community level were interested in providing objective quality-of-life data.

Table 1 Measures of social control and cohesion for aggregate urban and rural areas, pilot and first follow up year

\begin{tabular}{llll}
\hline & & Pilot year & Year one \\
\hline Social control & Urban & 17.8 & 19.2 \\
& Rural & 12.8 & 12.9 \\
Social cohesion & Urban & 14.8 & 16.2 \\
& Rural & 12.91 & 12.95 \\
\hline
\end{tabular}

Table 2 Some of the obstacles and assets to community health identified by respondents in preliminary research

\begin{tabular}{|c|c|c|}
\hline & Urban & Rural \\
\hline bstacles & $\begin{array}{l}\text { Community involvement; Infrastructure; Youth } \\
\text { outreach needed; People do not keep up } \\
\text { property; No access to resources; Ineffective } \\
\text { law enforcement; No jobs; Crime; Education }\end{array}$ & $\begin{array}{l}\text { Gangs; Lack of activities for youth; Lack of } \\
\text { community involvement; Needs improved } \\
\text { infrastructure; No access to resources; } \\
\text { Inadequate law enforcement; Lack of jobs; }\end{array}$ \\
\hline Assets & $\begin{array}{l}\text { Like the way the neighborhood looks; } \\
\text { Community cooperation/respect; Peace and } \\
\text { quiet; The people; Access to community } \\
\text { groups; Privacy; Ethnic and cultural diversity }\end{array}$ & $\begin{array}{l}\text { The people; Small community; Quiet, peaceful; } \\
\text { Community involvement; General ambience; } \\
\text { Access to groups/Resources; Economic } \\
\text { stability; Relatives nearby }\end{array}$ \\
\hline
\end{tabular}


Because interview respondents often requested an explanation as to what purpose or end result pertained to particular sets of questions, it was important to develop a project that was of significance to local residents and to incorporate indicators relevant at the local level. Open-ended questions, in particular, where individuals could discuss why they volunteered or participated in civic life, share their opinions about obstacles to community wellbeing, and/or praise what was working well, appeared to offer a welcomed vehicle for community voice. Questions were incorporated that permit residents to share their ideas about obstacles to community wellbeing and/or what is working well in their community. Creating a feedback loop back to residents about what they perceive to be assets or obstacles to community wellbeing is an evolving dimension of the research project.

As illustrated above, preliminary data suggests tremendous potential for community consensus around shared views and concerns. Further, key community stakeholders have been able to suggest additional indicators during our pilot phase. However, these processes run the risk of being time and resource intensive and may create non-standardized data that prevents regions from being compared. The team will continue to explore this tension and assess the potential for ongoing community participation as the research develops.

An important, yet an often ignored aspect of community-based research projects is student involvement with the process. Academic researchers, students, and universities are all stakeholders in community-engaged research. Universities, along with local governments and nonprofit agencies are faced with increasing pressure to demonstrate results. In the case of higher education, universities are charged with producing a well-informed and prepared workforce, able not only to achieve individual success but also to participate in the life of their communities. The PAC project works to develop capacity and participation of local citizens in part by training the next generation of community leaders and workers. Teaching and learning about community engagement, social issues and public policy is difficult to do in a social vacuum. The PAC project employs undergraduate and graduate students as researchers, assisting in almost every phase of the project. By incorporating students in the research process, PAC collaborators are practicing a model of communitypraxis education on a grand scale (Varlotta 2008). Whereas the process of communitypraxis encourages students to think about being part of groups, how to build relationships and to think critically about communities on campus, our project requires students to extend this practice to broader community contexts. Participation in the PAC research process provides students with a valuable educational experience beyond the traditional classroom setting. Extending students' understanding of community beyond the campus walls is an extremely important process to insure they become informed engaged stakeholders in their communities now and after college.

Moreover, the PAC project enables student research assistants the opportunity to hone their research skills by developing baseline data, collecting and analyzing the information as well as networking with key community organizations and government agencies whose focus overlaps with PAC project research interests. Although the research team did not necessarily start with the goal of increasing political engagement among student research assistants, anecdotally this appears to be the case. Students reported developing some important relationships with key community leaders, and a greater sense of commitment to improving the lives of others and being involved in local political affairs. The PAC project hopes to continue this model of student involvement, as this political engagement among students is seemingly one more benefit of community-based research (Cook 2008).

The PAC research is being developed during a time when substantial governmental and public attention is being directed to addressing the region's endemic disparities. The tenth and newest campus of the University of California was located in Merced in the heart of 
the San Joaquin Valley in response to the needs of the region, its rapid transformation, and its future potential. Major non-profit foundations such as the Irvine Foundation, Hewlett Foundation and The California Endowment are also investing resources in the region. The academic researchers on the PAC team are actively involved with at least one of various major initiatives to foster community health in the region. In this regard, the project directly and indirectly engages with multiple stakeholders who have a role in shaping the future wellbeing of local communities in the San Joaquin Valley.

\section{Conclusion}

The PAC team was initially formed to track quality-of-life measures in the Central San Joaquin Valley, the research activity directly stemming from an executive order by Governor Schwarzenegger. As such, the PAC's research consists of a longitudinal study, where a cross-sectional sample of geographical units and their populations are selected and surveyed, and information is collected at regular time intervals.

As earlier researchers recognized, "(i)n order to move from indicators to action, projects must examine the causes behind the symptoms, a process that could lead the indicators movement in a new direction." (Cobb and Rixford 1998, p. 2). As outlined above, for the research design of the PAC project the selection of indicators was motivated by a host of stakeholders ranging from state government to local residents. By incorporating indicators that provide quantitative quality-of-life data as well as qualitative data on perceptions, attitudes, values, and practices, PAC aspires to not only create a measure of community health but to identify areas where local residents reach consensus about issues and priorities that can lead to community action to ameliorate community health and individual and household wellbeing. Thus the idea behind the PAC project echoes the scholarship of others who advocate that social indicators not be an end in themselves, but a communityengaged problem solving tool. Florin and Wandersman (1990) explore this position by examining the potential of research in assisting community development and empowerment. "Community development represents an approach that facilitates individual and community capabilities, that attacks more than one problem at a time, and that fosters citizen efforts and citizen influence in decision making" (45).

To make the PAC research relevant not only to academic audiences but also to community problem solving efforts, we strive to make the results of the research available to the residents participating in the study as well as to other stakeholders, policy makers and to the general public. The team will continue to develop new strategies for further involving the community in the research process and in the dissemination of findings to influence policy initiatives pertaining to this important region of California.

Open Access This article is distributed under the terms of the Creative Commons Attribution Noncommercial License which permits any noncommercial use, distribution, and reproduction in any medium, provided the original author(s) and source are credited.

\section{References}

Ammerman, N. T. (2005). Pillars of faith: American congregations and their partners. Berkeley: University of California Press.

Anderson, E. (1990). Streetwise: Race, class and change in an urban community. Chicago, IL: University of Chicago Press. 
Badenhausen, K. (2009). Urban affairs America's most miserable cities. Forbes.com. http://www.forbes. com/2009/02/06/most-miserable-cities-business-washington_0206_miserable_cities_print.html. Retrieved May 30, 2009.

Bailey, D., \& McNally Koney, K. (1996). Interorganizational community-based collaboratives: A strategic response to shape the social work agenda. Social Work, 41(6), 602-611.

Baldassare, M. (2006). PPIC statewide survey: Special survey of the central valley. June 2006. Public Policy Institute of California. Sacramento, California.

Bengiamin, M., et al. (2005). Health in the heartland: Responding to the crisis. Fresno: Central Valley Health Policy Institute, California State University.

Brady, H. E., Verba, S., \& Schlozman, K. L. (1995). Beyond SES: A resource model of political participation. The American Political Science Review, 89(2), 271-294.

California Partnership for the San Joaquin Valley. (2006). The San Joaquin Valley: California's 21st Century Opportunity. Strategic Action Proposal. October 2006.

Cobb, C., \& Rixford, C. (1998). Lessons learned from the history of social indicators. San Francisco: Redefining Progress.

Congressional Research Service. (2005) California's San Joaquin Valley: A region in transition. December $12,2005$.

Cook, C. (2008). Beyond service: Community-based research and political engagement. In S. Cahill Tannenbaum (Ed.), Research, advocacy and political engagement: Multidisciplinary perspectives through service-learning. Sterling, VA: Stylus.

Dluhy, M., \& Swartz, N. (2006). Connecting knowledge and policy: The promise of community indicators in the United States. Social Indicators Research, 79, 1-23.

Docherty, I., Goodlad, R., \& Paddison, R. (2001). Civic culture, community and citizen participation in contrasting neighbourhoods. Urban Studies, 38, 2225-2250.

Duneier, M. (1999). Sidewalk. New York, NY: Farrar, Staus and Giroux.

Epley, D. R., \& Mohan, M. (2008). A method of assembling cross-sectional indicators into a community quality-of-life. Social Indicators Research, 88, 281-296.

Florin, P., \& Wandersman, A. (1990). An introduction to citizen participation, voluntary organizations, and community development: Insights for empowerment through research. American Journal of Community Psychology, 18(1), 41-54.

Galaskiewicz, H., \& Bielefeld, W. (1998). Non-profit organizations in an age of uncertainty: A study of organizational change. Piscataway, New Jersey: Aldine Transaction.

Kitchen, P., \& Muhajarine, N. (2008). Quality-of-life research: New challenges and new opportunities. Social Indicators Research, 85, 1-4.

Larson, O. (1978). Values and beliefs of rural people. In T. R. Ford (Ed.), Rural U.S.A.: Persistence and change. Ames, IA: Iowa State Press.

Marinrogers, N., Rausch, E., \& Mattessich, P. (2009). Communities that don't bowl in the fog. Contexts, $8(1), 26-31$.

Muhajarine, N., Labonte, R., Williams, A., \& Randall, J. (2008). Person, perception, and place: What matters to health and quality-of-life. Social Indicators Research, 85, 53-80.

Paul, K. (2009). A newsweek special report: The valley of shadows. Newsweek. August, 2009. http://www.newsweek.com//id/211399. Accessed September 6, 2009.

Reily, C. (2009). County jobless rate rises slightly in June. Merced Sun-Star. www.mercedsunstar.com/ 167/v-print/story/957189.html. Retrieved July 20, 2009.

Sampson, R. J., Raudenbush, S., \& Earls, F. (1997). Neighborhoods and violent crime: A multilevel study of collective efficacy. Science, 277, 918-924.

Sheehan, T. (2009). Fresno County Jobless Rate Up to 15.2\%. The Fresno Bee. http://www.fresnobee.com/ business/story/1542795.html. Retrieved July 20, 2009.

Sherman, J. (2008). Coping with rural poverty: Economic survival and moral capital in rural America. Social Forces, 85(2), 891-913.

Snyder, A. R., \& McLaughlin, D. K. (2004). Female-headed families and poverty in rural America. Rural Sociology, 69(1), 127-149.

Swain, D., \& Hollar, D. (2003). Measuring progress: Community indicators and the quality of life. International Journal of Public Administration, 26(7), 789-814.

Varlotta, L. E. (2008). Teaching students how to talk about, think about, and do community. NASPA Journal, 45(3), 327-349.

Wilson, W. J. (1996). When work disappears: The world of the new urban poor. New York, NY: Knopf. 